\title{
Herbaceous invaders in temperate forests: a systematic review of their ecology and proposed mechanisms of invasion
}

\author{
Mia Wavrek $\cdot$ J. Mason Heberling $\cdot$ Songlin Fei $\cdot$ Susan Kalisz
}

Received: 7 December 2016/Accepted: 12 May 2017/Published online: 7 June 2017

(C) The Author(s) 2017. This article is an open access publication

\begin{abstract}
We present a systematic literature review of exotic understory forest herbaceous invasions with a focus on the forests of East Asia (EAS) and Eastern North America (ENA), two dominant regions of the north temperate deciduous forest biome. We examined the biogeographic origins of herbaceous invaders in EAS and ENA forests, summarized their life histories and ecology, and compiled the relevant literature on the 10 leading mechanistic hypotheses proposed for these invasions. We asked whether invasions of EAS and ENA forests by herbs are shared between regions, and
\end{abstract}

Guest Editors: Andrew Liebhold, Eckehard Brockerhoff and Martin Nuñez / Special issue on Biological Invasions in Forests prepared by a task force of the International Union of Forest Research Organizations (IUFRO).

Electronic supplementary material The online version of this article (doi:10.1007/s10530-017-1456-7) contains supplementary material, which is available to authorized users.

M. Wavrek · J. M. Heberling · S. Kalisz $(\bowtie)$

Department of Ecology and Evolutionary Biology,

University of Tennessee, Knoxville, Knoxville,

TN 37919, USA

e-mail: skalisz@utk.edu

\section{J. M. Heberling $\cdot$ S. Kalisz}

Section of Botany, Carnegie Museum of Natural History,

Pittsburgh, PA 15213, USA

S. Fei

Department of Forestry and Natural Resources, Purdue

University, West Lafayette, IN 47907, USA whether a common suite of ecological traits unite these invaders into a functionally distinct group. In a focused summary of the empirical literature, we investigated if leading hypothesized mechanisms for biological invasions at large are also invoked and supported for this ecologically important, but relatively understudied, group of species. In contrast to ENA, forest invaders in EAS are overwhelmingly herbaceous $(78 \%$ of forest invasions vs. 34\% for ENA) and originate from different regions. Plant families represented and species traits between regions differed. Within a single species, multiple invasion mechanisms were often supported, highlighting the need for future research that simultaneously investigates multiple mechanistic hypotheses. Further, because results for a single invader often differed across space and time, a shift in focus to incorporate the complex dynamics across temporal and spatial scales with the consideration of spatial heterogeneity and the interplays among natural and anthropogenic factors to study exotic invasions is needed.

Keywords Herbaceous temperate forest invaders · Functional traits · Invasion mechanisms · Systematic review $\cdot$ Automated content analysis $\cdot$ Eastern North America $\cdot$ East Asia

\section{Introduction}

Understory vegetation layers in temperate forests across the globe provide key ecological and functional 
roles, exhibit high levels of biodiversity, and are valued for their aesthetic beauty. The understory contains both the woody seedlings that are the advanced regeneration of the midstory shrub and overstory tree layers (Baker and Van Lear 1998), but it is the more diminutive herbaceous species that comprise the highest biodiversity functional group in temperate forests. In forests of Eastern North America, for example, it has been estimated that the herbaceous layer contains three- to 250-times more species than the tree and shrub layers and collectively can account for up to $80 \%$ of the forest plant species richness (Gilliam 2014). This diverse herbaceous layer also includes rare species with unique traits (Jolls 2003). Despite their low abundances, rare species in high diversity ecosystems support unique ecosystem functions and services that are highly vulnerable to disruption and loss (sensu Mouillot et al. 2013). Thus, degradation of the herb layer has been equated to significant forest biodiversity loss (Jolls 2003). Further, herbaceous communities are known to profoundly affect forest productivity and the maintenance of plant biodiversity (e.g. Van der Heijden et al. 1998), biogeochemical and nutrient cycles (e.g. Zak et al. 1990; Tessier and Raynal 2003; Mueller et al. 2012; Neufeld and Young 2014; Welch et al. 2007; van der Heijden and Horton 2009; but see Rothstein 2000), and ecosystem services (reviewed in Gilliam 2007). Understory herbaceous species also provide critical food resources, physical structure, and habitat heterogeneity (Roberts and Gilliam 2003; Roberts 2004) that support biodiversity of other ecologically important plant groups and in other trophic levels including insects, birds and mammals (e.g. Tews et al. 2004). In addition to the scientific and conservation importance, society places intrinsic value on charismatic herb species for recreational and aesthetic reasons (e.g., parks and trails across the US known and named for Trillium or other wildflower populations).

Taken together, these factors make the herbaceous layer in temperate forests targets of high conservation effort worldwide (Jolls 2003; Spyreas and Matthews 2006). While the temperate forest is assumed to be resistant to invasion and resilient to perturbations, this assumption is rarely tested due to the need for both baseline data and subsequent long-term data collection (Taverna et al. 2005). Yet, where sufficient data exist to examine changes in species over these long time scales, rare native species' local extinction, native species decline, and non-native species enrichment are increasingly demonstrated for both woody and herbaceous ground layer plants in temperate forests (e.g. Rooney et al. 2004; Taverna et al. 2005; Wiegmann and Waller 2006; Rogers et al. 2008; Winter et al. 2009; Martin et al. 2010; Baeten et al. 2010; Royo et al. 2010). Together, the trend for biotic homogenization (sensu Qian and Ricklefs 2006; Clavel et al. 2011) and biodiversity loss (e.g. Rogers et al. 2008; Keith et al. 2009) in the understory is well supported.

The shift in forest community composition is likely due to multiple human-mediated forces including habitat fragmentation, changes in adjacent land use patterns, deer overabundance, $\mathrm{N}$ deposition, climate change, and species invasions (including exotic pathogens, pests, plants, and earthworms) (reviewed in Bryant et al. 1997; Friedland et al. 2004). While such environmental change can act (or interact) differently depending on habitat types and spatial scales to influence an invaders' local success (e.g. Debinski and Holt 2000; Rooney et al. 2004), at the global scale, species invasions are among the strongest agents of environmental change (Sala et al. 2000; Ehrenfeld 2010; Fei et al. 2014; Murphy and Romanuk 2014). Invaders alter species interactions, biodiversity, ecosystem functioning, and biogeomorphology (Hooper et al. 2005; Ehrenfeld 2010; Vilà et al. 2011; Devine and Fei 2011; Fei et al. 2014; Walsh et al. 2016). Interestingly, a large body of plant invasion research focuses primarily on the invasion of systems with increased disturbance levels or frequencies and/ or high light and soil resource availability (Alpert et al. 2000; Daehler 2003), including many grasslands, marshes, old fields, and agricultural environments. And because the growth rates of understory plants in northern temperate forests are resource-limited, particularly by light and nutrient ( $\mathrm{N}$ and $\mathrm{P}$ ) supply (Elser et al. 2007; LeBauer and Treseder 2008), the temperate forest understory has generally been considered relatively more difficult to invade. Yet, excess $\mathrm{N}$ deposition can alter many species interactions in forests, which can favor nitrophilous invasive species and ultimately drive declines in understory biodiversity (Gilliam 2006), resulting in the extensive invasion of exotic plants (Iannone et al. 2015; Oswalt et al. 2015).

Despite the current lack of a unified explanation for why forests are invaded, the number of studies 
documenting understory invasion continues to grow (e.g. Rooney et al. 2004; Wiegmann and Waller 2006; Rogers et al. 2008; Winter et al. 2009; Kalisz et al. 2014). Even intact temperate forest understories are not immune to invasion (reviewed in Martin et al. 2009). In fact, it is estimated that nearly half of the forests in the eastern U.S. are invaded by exotic plants (48\%; Iannone et al. 2015). Further, when understory communities are invaded, some of these exotic plant species can form dense monospecific layers (or 'recalcitrant layers' sensu Royo and Carson 2006) that replace the native herbaceous species, interfere with woody and herbaceous seedling establishment, and halt forest succession. Together, these findings establish that the stability of forest communities and competitiveness of understory perennials are less robust than widely believed and that anthropogenic forces have likely altered the invasibility of this important ecosystem type with important consequences for understory biodiversity.

For forests, previous reviews have summarized tree or shrub invasions (Lamarque et al. 2011; Richardson and Rejmánek 2011, respectively), or individual herbaceous invaders (Rodgers et al. 2008; Warren et al. 2011; Luken 2014), but a broader literature synthesis for understory herbaceous invasions is lacking (Gilliam 2007). In this paper we seek to summarize the ecological characteristics of the nonnative herbaceous species that actively invade this ecologically important forest layer and gain perspectives from the literature on the leading invasion hypotheses that might explain their success (Table 1). To gain first insights into how and why forest herbaceous invaders succeed, we focus on the temperate forest understories of eastern North American and East Asia. Several reasons motivate us to target herbaceous invaders of these forests. First, temperate deciduous forest understory of Eastern North America and East Asia have common evolutionary origins (Wen 1999). Since the era of Linnaeus, botanists have recognized close phylogenetic affinities and ecological similarities between the temperate floras of East Asia (hereafter EAS) and Eastern North America (hereafter ENA) (reviewed in Boufford and Spongberg 1983; Wen 1999). ENA and EAS share similar climatic niches (north temperate), vegetation types (primarily deciduous forest biome), and evolutionary histories (Qian and Ricklefs 1999; Donoghue and Smith 2004). Despite these similarities, a clear diversity bias exists today, with EAS comprising more plant families, genera, and species than ENA (Guo 1999). Within 58 plant genera shared between regions, EAS has nearly twice the number of species than ENA, a pattern likely due to large-scale historical differences in extinction rates between regions rather than habitat differences (Qian and Ricklefs 2000). Second, although a few herbaceous native species can form a 'recalcitrant' monolayer in the temperate forest understory (see Table 1 in Royo and Carson 2006; Royo et al. 2010), many herbaceous invaders are capable of forming dense monocultures (Fig. 1). It is unclear the degree to which trait characteristics and invasion mechanisms contribute to this invader monodominance. Third, we are specifically interested in herbaceous invaders because they are within the same plant functional groups as native forest herbaceous species, and presumably share functional roles, yet they are putative agents of temperate forest biodiversity decline. Identifying potential patterns behind the success of herbaceous invaders could significantly contribute to the conservation of forest biodiversity.

Motivated by these unanswered questions, we utilized two different but complementary approaches. First, we used recently published invasive species lists to specifically summarize the geographic origins of EAS and ENA herbaceous invaders in forests and ask whether invaders from EAS and ENA regions reciprocally establish and whether particular regions are more likely to contribute forest herb invaders. Second, we conducted a systematic literature review, both manually and via automated content analysis (ACA, Nunez-Mir et al. 2016), to determine if the specific species that invade EAS and ENA forests share mechanisms of invasion. With this approach we address the following main questions: (1) What major ecological concepts have been studied around these species? (2) Do forest herb invaders share common life history and ecological characteristics, or alternatively, are these invaders functionally diverse? Do these invaders also originate from the same regions? (3) Do these species share a common mechanism, or set of mechanisms, proposed to explain their invasion? Are there temporal trends of these common mechanisms studied in these species? 
Table 1 Mechanistic hypotheses commonly invoked to explain exotic invasion success

\begin{tabular}{|c|c|c|}
\hline Invasion mechanism & Description of mechanism & References \\
\hline
\end{tabular}

Novel weapons

Allelopathy

Competition (including lack of biotic resistance)

Disturbance (including disruption of species interactions and invasional meltdown)

Enemy release

Evolutionary change (including rapid evolution)

Hybridization

Plasticity

Soil feedback

Inherent traits
Attributes an invader's success to its unique morphological or biochemical traits that repel herbivores or hamper competitors, thereby sharpening the competitive edge of the invader relative to native species. Includes low palatability/ herbivore resistance, mutualism disruption

A specific case of Novel Weapons. Attributes invasion success to the release of chemical compounds that have harmful effects on the members of the naïve, recipient plant community

Attributes invasion success to direct interactions (or lack of) with resident community, such as herbivores, disease or plant competitors, which suppress invader establishment and/or population growth

Implicates human or natural disturbance of the native community and changes in abiotic and biotic conditions in invasion process. Related are the various hypotheses about human management decisions that result in overabundant ungulates (e.g. cows, sheep, deer, elk). High population sizes of these animals alter the abiotic and biotic conditions experienced by invaders. In temperate regions worldwide, the loss of apex predators has resulted in irruption of ungulate populations

Attributes the success of invaders to their escape from the enemies in their home range that control their population growth, combined with the lack of or fewer enemies relative to resident species in the invaded range

Adaptations and genetic changes that occur post introduction in invaders allow for establishment and spread in introduced range.

Post-introduction hybridization between closely related native and exotic taxa can produce high fitness genotypes combining traits of both species that allow greater diversity of habitats to be occupied

Phenotypic flexibility of an organism or species to changes in its current environment or across a range of habitats

Invader-induced changes in soil properties influence the performance of native plants and/or itself (e.g., alter nutrient cycling)

Focuses on intrinsic attributes of plant species' (phenology, high reproductive output, mating system) and its physiological responses (high photosynthetic rate, wide irradiance regimes, resource uptake)
Callaway and Ridenour (2004)

Hierro and Callaway (2003)

Levine et al. (2004), Verhoeven et al. (2009)

Maron and Vila (2001), Hierro et al. (2006), Vavra et al. (2007), Simberloff and Von Holle (1999)

Keane and Crawley (2002)

Blossey and Notzold (1995), Prentis et al. (2008), Whitney and Gabler (2008)

Abbott (1992), Ellstrand and Schierenbeck (2000)

Davidson et al. (2011)

Ehrenfeld (2003), Wolfe and Klironomos (2005), Meisner et al. (2014)

van Kleunen et al. (2010)

Hypotheses invoking similar causal mechanism are grouped under a single heading. N.B. Hypotheses are not mutually exclusive 


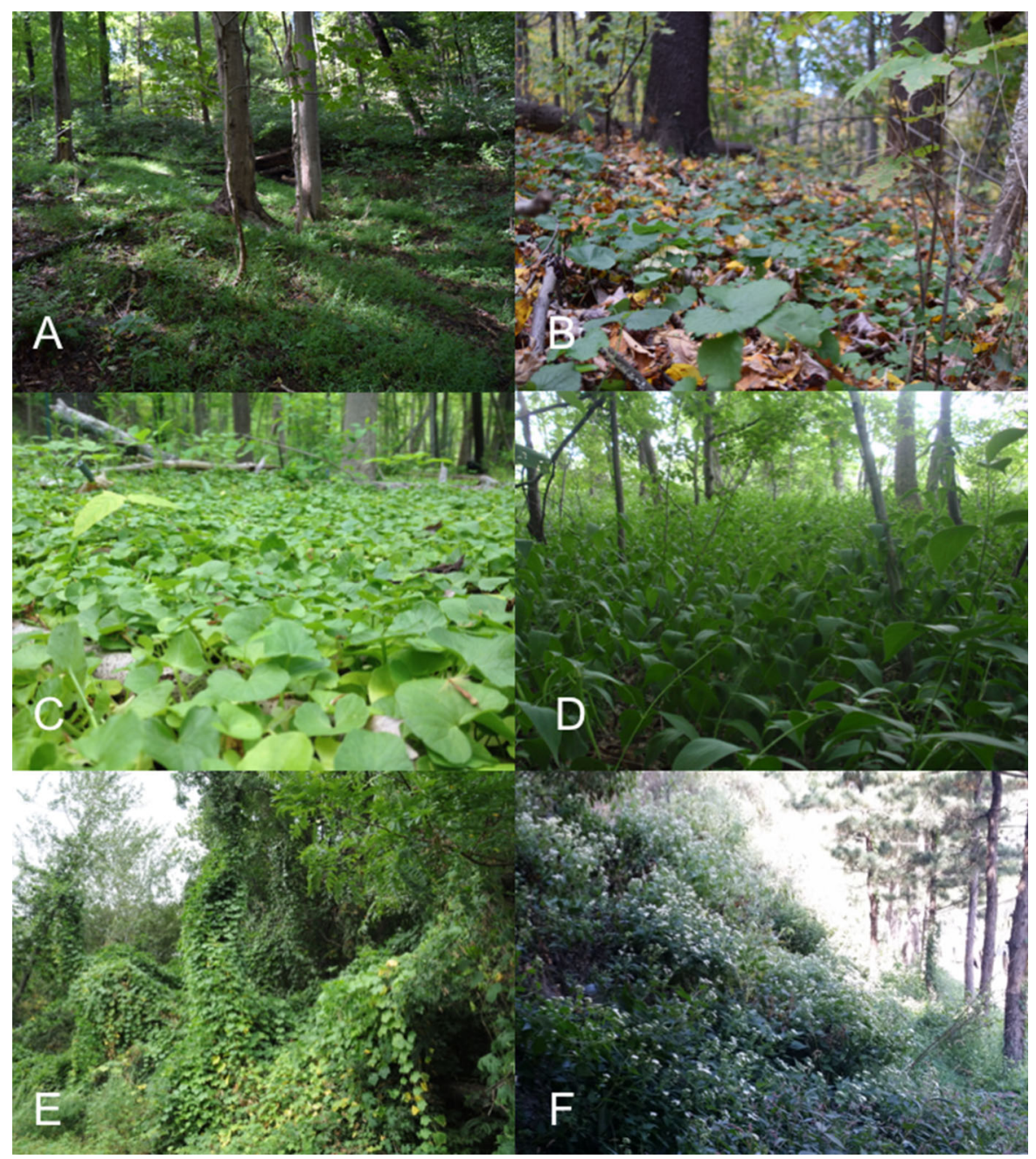

Fig. 1 Representatives of herbaceous invasions in temperate forests. a Microstegium vimineum (Poaceae), a grass native to East Asia, forms a monolayer in many shaded, mesic understories across northeastern USA. b Alliaria petiolata (Brassicaceae), a biennial forb native to Eurasia, form rosettes across eastern North American forests that persist in the forest floor in autumn to bolt and reproduce the following spring. c Ficaria verna (Ranunculaceae), a Eurasian native, forms thick, continuous mats in early spring, especially in riparian

\section{Methods}

Species selection

Naturalized herbaceous species lists for East Asia (EAS; China, Korea, Russian Far East) and Eastern North America (ENA) were obtained from Heberling et al. (2017b) and Fridley (2008). From those lists, we assembled a subset containing only non-native or naturalized species reported in forests (broadly defined floodplain forests across eastern North America. d Cynanchum rossicum (Asclepiadaceae), a perennial vine native to eastern Europe, can form dense monolayers in forest understories in northeastern USA. e Sicyos angulatus (Cucurbitaceae), an annual vine native to eastern North America, invades forest edges in South Korea. f Ageratina altissima (Asteraceae), a perennial understory forb native to eastern North America, invades forests and forest edges in South Korea. Photos credits: a-d, J.M. Heberling; e, f, H. Lee

as any shaded habitat with substantial tree cover) that were designated as 'invasive' by the primary sources (i.e., naturalized species that reproduce and spread over a large area).

\section{Ecological traits of EAS and ENA invaders}

To determine whether herbaceous invaders share common characteristics that potentially aid in their invasion, we compiled available species-level trait 
data from primary literature sources and online invasive species databases. Invasive species were categorized according to growth habit (forb, vine, or grass), life history (annual, biennial, and/or perennial), reproductive strategy [sexual and/or asexual (clonal, vegetative, apomictic)], whether the species is selfcompatible (SC) or self-incompatible (SI), modes of pollination [wind and/or animal (including insects, birds, mammals)], the presence/absence of a longlived seed bank and seed dispersal mode (wind, water, animal, gravity, and/or ballistic). Information for every category was not available for every species. These characteristics were chosen due to accessibility and have all been implicated in both the classic (Baker 1965) and recent (van Kleunen et al. 2014) literature as indicators of invasion success.

Literature review and invasion mechanisms

We performed both traditional and automated systematic review approaches to (1) obtain an understanding of the general ecological concepts associated with the major invasive plants in ENA and EAS, (2) synthesize key invasion mechanisms that might be used explain forest herb invasions, and (3) examine the temporal dynamics of these invasion mechanisms that have been investigated. The combined approach of both an ACA, which is relatively objective and inclusive, and a manual systematic review, which can better handle complex and non-mutually exclusive concepts, allowed us to gain a comprehensive understanding of studies conducted on these targeted EAS and ENA invaders.

\section{Selection of literature}

From July to November 2016, we conducted searches of the Web of Science database (Thompson Reuters 2016) using each species' scientific name. We refined our searches using the Topic search terms "Genus AND species AND inva*" to exclude publications unrelated to invasion. We also searched taxonomic synonyms. Publications were excluded if they were not invasion-related, if they focused strictly on management or biological control, or if authors did not investigate at least one proposed mechanisms of invasion. In addition to mechanistic studies, we also noted studies that explored the impacts (positive and negative) of invaders on (native) biodiversity, which we evaluated separately (Fig. S1).

\section{Literature review}

\section{Automated content analysis (ACA)}

We conducted the ACA on the abstracts of all aforementioned literature using Leximancer 4.0 (Leximancer Pty Ltd, Brisbane, Australia), a word mining software system that allows the review of a larger body of literature to discover concepts and to identify their relationships (Smith and Humphreys 2006). We used ACA for two primary purposes. The first was to obtain an understanding of common ecological concepts studied in these literature, and the second was to gain an understanding of temporal dynamics of key invasion mechanisms that have been studied and their associations with common invaders. Automated Content Analysis is a three-staged process that includes concept identification, concept definition, and text classification (Nunez-Mir et al. 2016). We started the ACA process by performing an unsupervised automated concept seed identification to identify the majority of concepts predominantly present within the reviewed abstracts using a two-sentence block scanning. We then refined concepts by removing neutral concepts (e.g., study, identify) and combining concepts of similar meanings (e.g., alter and change), which provided a group of refined key concepts to be used for the next step (Table S1). By inspecting relationships between key invasion mechanisms and the refined concepts, we formed a set of thesauruses for each of the invasion mechanisms that we manually reviewed (see details in the following section) by linking highly relevant concepts to each hypothesis (Table S2). Note that we did not include the Inherent Traits and the Plasticity mechanisms into the ACA analysis, as "traits" was a prevalent concept throughout the core of the reviewed literature. To understand the temporal dynamics of the hypotheses studied, we further tagged the results with the year each research article was published.

\section{Manual systematic review}

For each publication, we manually classified the study type (experimental, observational, descriptive), location (field, lab, common garden/greenhouse), and 
mechanism(s) of invasion invoked by study authors. We grouped the common invasion mechanisms into ten non-mutually exclusive topics that dominate the hypothesis-based invasion literature (Table 1). For the mechanism(s) investigated in each study, we recorded whether the mechanism was supported, lacked support, or had inconclusive or mixed support based on author-reported findings and conclusions. Our approach does not directly attribute mechanisms or traits to a species' invasion success. Rather our goal is to shed light on existing hypotheses and commonly investigated mechanisms and to find general patterns. We then fed all reviewed invasion mechanisms (except Inherent Traits and Plasticity) back into ACA to depict their temporal dynamics and their associations with other invasion concepts.

For publications investigating biodiversity impacts (not necessarily mechanistic), we recorded whether biodiversity loss was supported (invader has negative impact), lacked support (invader has a positive impact or no impact), or had mixed or inconclusive results (impact is context dependent). The final literature review included 234 qualifying publications for 25 of the 49 ENA species and 95 publications for 17 of the 38 EAS species (Fig. S1; Table S3; Table S4). Publications that focused solely on biodiversity impacts and did not investigate mechanisms (13 for ENA and 1 for EAS) were removed from mechanism results.

\section{Results}

Composition and biogeography of invaders

About $81 \%$ (2131 species) of all non-native plants species in ENA are herbaceous (Fridley 2008), only $14 \%$ (293) of which are considered 'invasive' (i.e., actively spreading). Most of these species invade open, managed, and/or roadside habitats (Fig. 2). Herbaceous invaders found in ENA forests, defined broadly as habitats with significant tree canopy cover, include 44 species (10\% of total invasive pool; Table 2), and originate primarily from north temperate regions (Fig. 3). Poaceae (grasses) is the single most invasive herbaceous plant family in ENA (18\% of all herb invaders), but 22 additional families are also represented (Fig. S2a).
EAS non-natives are also dominated by herbaceous species (89\% of all non-natives; 1145 species), but compared to ENA, herbaceous non-native species are much more invasive in EAS ( $42 \%$; compare to $14 \%$ in ENA). Although EAS has more documented invaders than ENA overall (531 vs. 449 species), EAS has far fewer invaders specifically in forests (only 49 vs. 129 species); however, a larger proportion are herbaceous in EAS (78\%; 38 species) compared to ENA forests (34\%; 44 species; Table 2; Fig. 2). Forest herb invaders in EAS overwhelmingly belong to the plant family Asteraceae (Fig. S2b). Also in sharp contrast to ENA, EAS forest herb invaders are dominated by species that originated in Central and South America (Table 2; Fig. 3b). Only 18\% (7 species) of invasive forest herbs in EAS are from the Circumboreal region (compared to $70 \%$ for ENA).

Invader traits

In both regions, the forb growth form was more common (63\% ENA; 89\% EAS) than grasses or herbaceous vines (Fig. 4a). Perennial invaders dominate ENA forests (69\%), while annuals and perennials were both common in EAS (Fig. 4b). In terms of reproductive ecology and pollination, sexually reproducing, animal- (insects and vertebrates) and wind-pollinated species were most common among EAS invaders (89, 84, and 25\%, respectively), but in ENA, invaders were primarily animal pollinated (100\% sexual, $85 \%$ animal pollinated; Fig. 4c,4d). Self-compatible species represented 78 and $67 \%$ of the ENA and EAS invaders, respectively (Fig. 4e). Seed dispersal modes were diverse among the forest invaders of both regions (Fig. 4g), with many species described as using multiple dispersal modes. Long-term seed dormancy is a common feature in herbaceous invaders of both regions: $90 \%$ of ENA and $94 \%$ of EAS species form seed banks (Fig. 4f).

\section{Key invasion concepts}

ACA identified that the majority of reviewed studies were conducted in the context of invasive-native relationship either through the population or community ecology perspective, which is evidenced through the high frequency of the native, population and community concepts (Fig. S4, Fig. S3). Interestingly, 

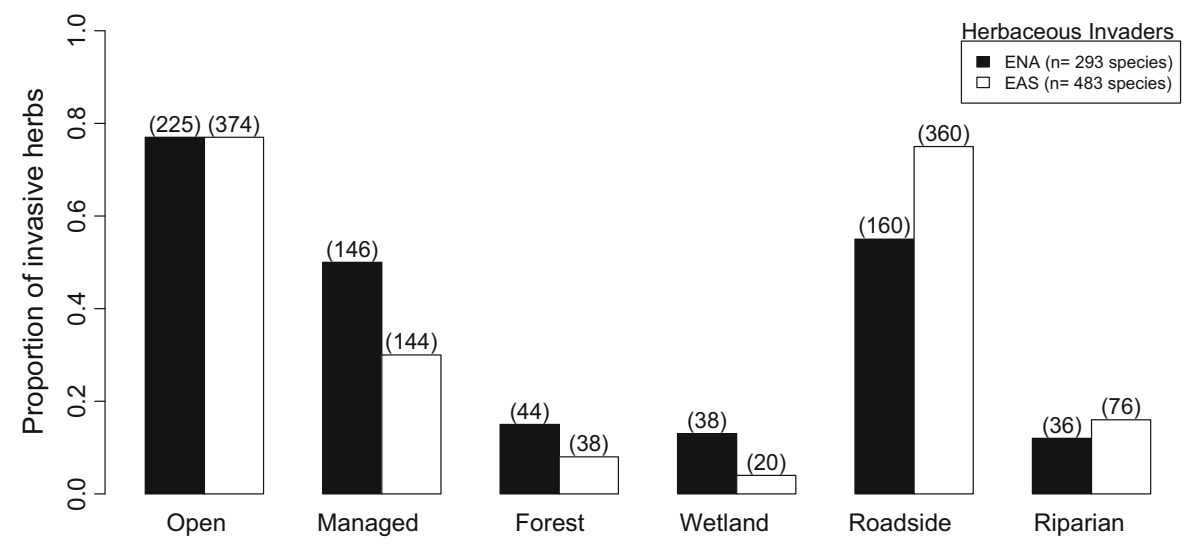

Fig. 2 Habitat-level invasion patterns for herbaceous species in Eastern North America (ENA; black) and East Asia (EAS; white). Bars show percentage of region invaders (herbs only) found in each habitat. Numbers in parentheses above each bar denote total number of taxa in each category. Note that invaders can invade multiple habitats (does not sum to $100 \%$ ). Habitats are broadly defined following Fridley (2008):

soil is a highly studied concept (ranked 2nd) in the literature reviewed. In addition, species traits related concepts such as growth, seed, seedling, biomass, germination, leaves, etc. are highly prevalent in the studied literature. Not surprisingly, the majority of these studies were conducted in forested ecosystems with some types of experiments (plots, experiments).

A closer inspection of the associations among the top ranked concepts and the other concepts further revealed insights about past invasion research (Fig. S3). Invasion related soil studies were closely linked to nutrient and moisture availability, changes in organic matter (accumulation, mineralization and carbon cycling), allelopathy effects, and microbial community composition. Studies on the growth concept have been focused on plant physiology, germination and survival of both native and invasive species, inhibition of invasives on natives, and responses to changes of conditions such as gap opening. Interestingly, the concept of population in our studied literature was strongly linked to gene flow and genetic diversity, overall tolerance and fitness, and range-related dispersal and local adaptation. Invasion related seed concepts were primarily linked to production, germination, and dispersal of invader seeds. As expected, the concept of forest was studied in close associations of forest conditions (interior vs. edge, mature vs. young, and canopy layer) and other stressors (fire and deer).
Open $=$ unshaded early successional habitats; managed $=$ unshaded habitats subject to regular anthropogenic disturbance; forest $=$ shaded habitats with significant tree canopy cover; wetland $=$ wet terrestrial habitats; roadside $=$ disturbed habitats associated with human transportation; riparian $=$ habitats associated with moving water

\section{Key invasion mechanisms}

Combining all studies from both regions, mechanistic hypotheses were tested a total of 417 times in 315 publications (221 ENA and 94 EAS). The rank of hypotheses as a proportion of the total publications that addressed the 10 mechanisms are: Inherent Traits (23\%), Disturbance (21\%), Competition (19\%), Allelopathy (19\%) Soil Feedback (13\%), Evolutionary Change (12\%), Plasticity (9\%), Enemy Release (7\%), Novel Weapons (6\%), and Hybridization (3\%). Overall, we found that $64 \%$ of all proposed mechanisms were supported by at least one study, $22 \%$ had mixed support or inconclusive results, and $14 \%$ lacked support. Because some studies examined multiple mechanisms, the total number instances of a mechanism being tested is greater than the number of papers in our review (i.e. 293 for ENA species; 124 for EAS species). Of the 293 tests of mechanisms for ENA invaders, 166 were supported (57\%), 85 had mixed or inconclusive results (29\%), and 42 lacked support (14\%), as reported by publication authors. For the literature on EAS invaders, 100 of the 124 tests found support (81\%), 9 had mixed or inconclusive results (7\%), and 15 lacked support (12\%) as reported by authors. In addition to the 315 studies on invasion mechanisms, we found a total of 40 studies (36 ENA and 4 EAS) that investigated biodiversity impacts at various trophic levels, with 55\% reporting negative 


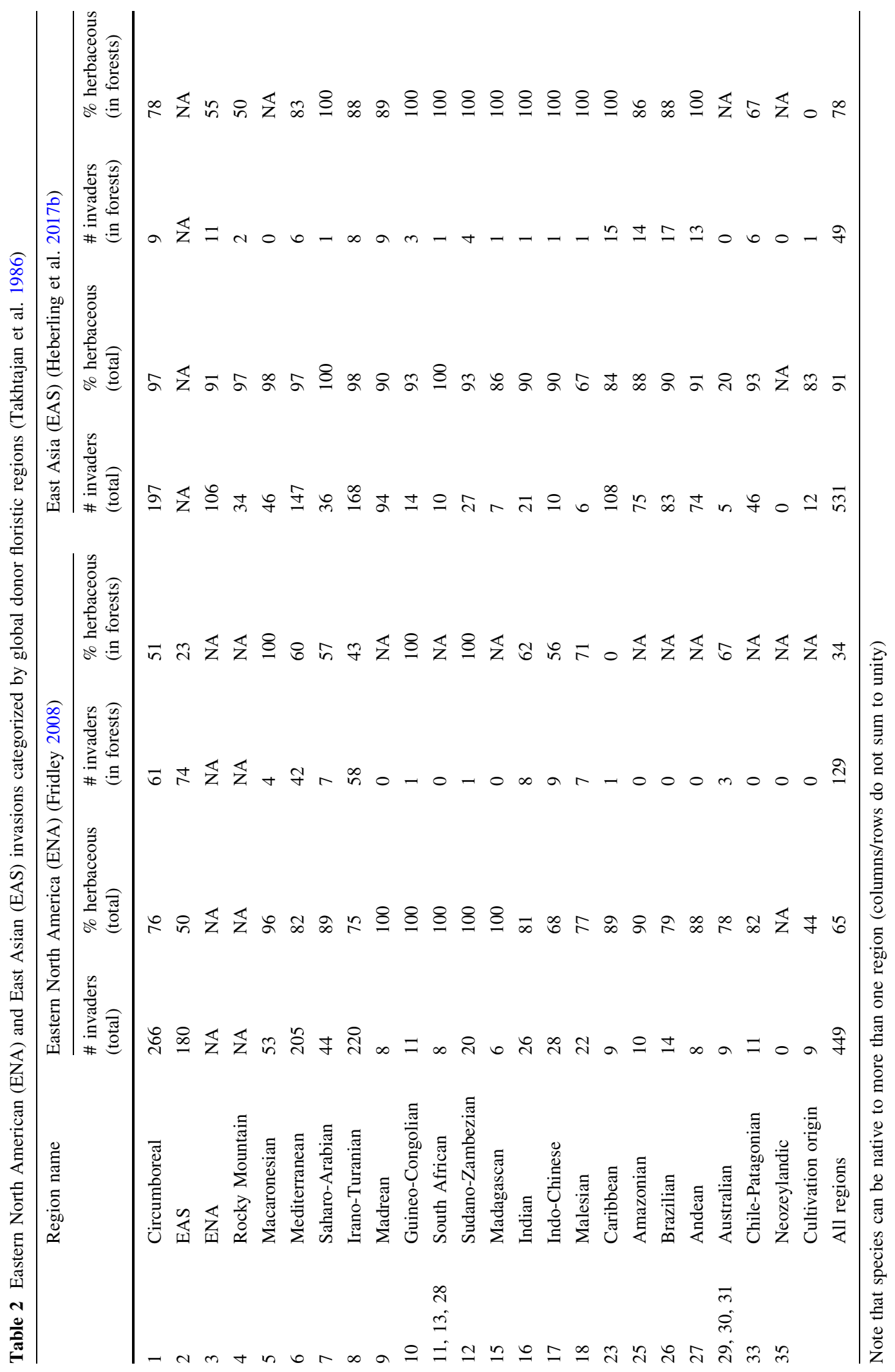


(a) E. North America (ENA)

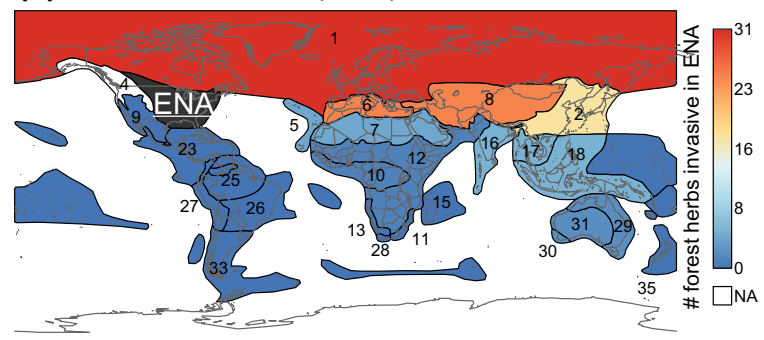

Fig. 3 Number of invasive forest herb species by donor region for a Eastern North America and $\mathbf{b}$ East Asia. Numbers refer to major phyto-geographic regions of Takhtajan et al. (1986; see (b) East Asia (EAS)

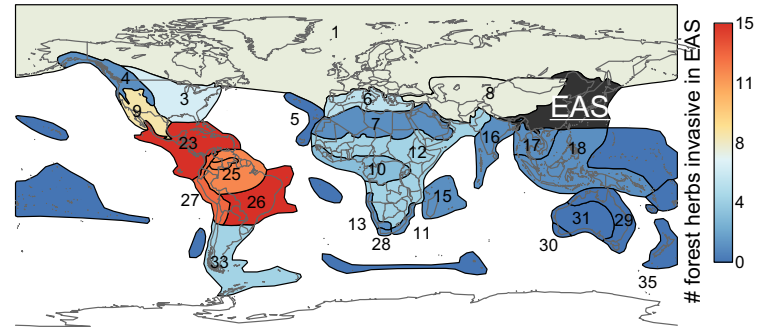

Table 2 for region names). Recipient regions are colored black. Note that taxa may be native to more than one region (a) Growth Habit
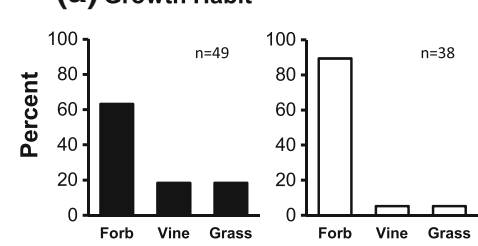

(b) Life History

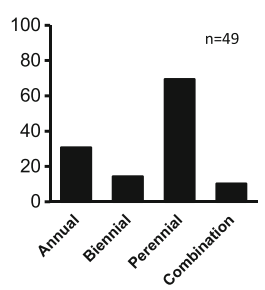

(c) Reproductive Mode

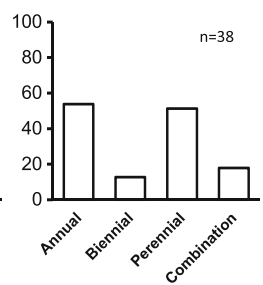

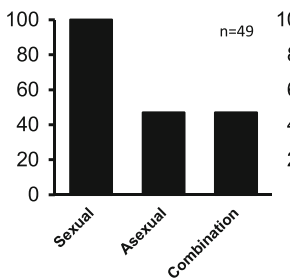

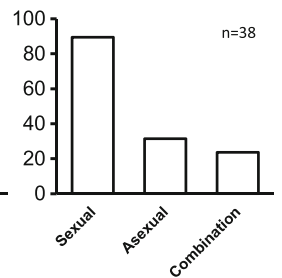

(d) Pollination Vector

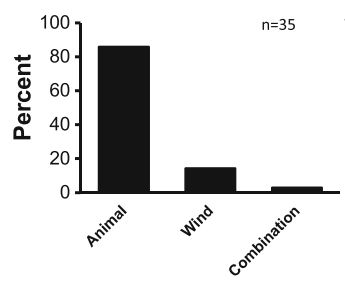

(f) Seed Bank

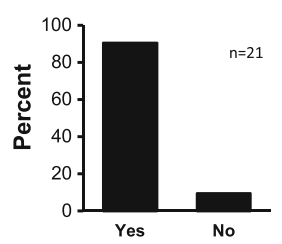

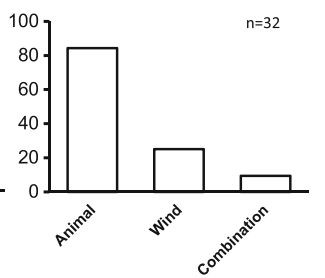

(e) Self Compatibility
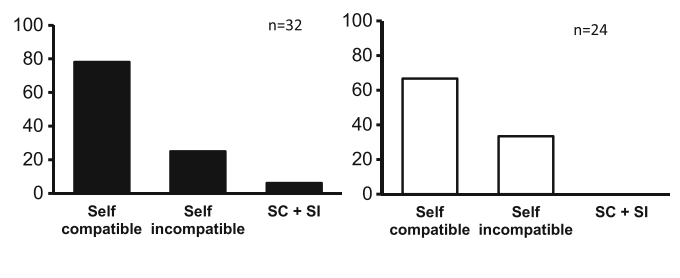

ENA Invaders $\square$ EAS Invaders

(g) Dispersal Mode
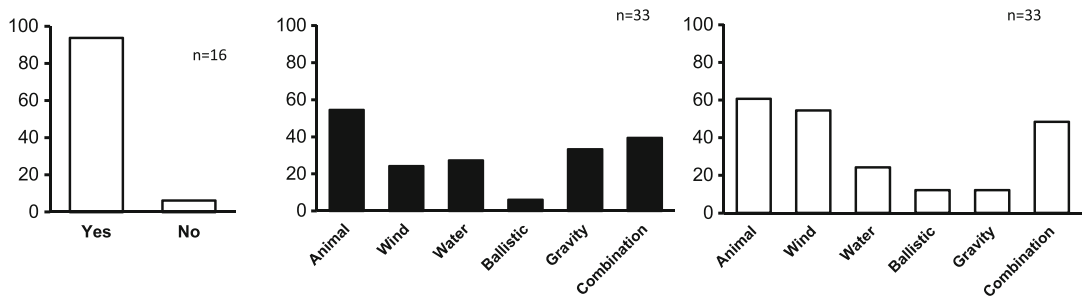

Fig. 4 Ecological characteristics for the herbaceous invaders of Eastern North America (ENA; black) and East Asia (EAS; white). Bars show percent of invasive species by category with the total number of species denoted in the upper right of each

impacts on biodiversity post-invasion, 33\% with mixed results, and $13 \%$ of publications found either no impact or positive impacts on biodiversity.

We found differences between the dominant mechanisms studied in each region (Fig. 5). For any given mechanism, the majority of results were in support in nearly all cases, the only exception being in the ENA plot. a Growth habit, $\mathbf{b}$ life history, $\mathbf{c}$ reproductive mode, $\mathbf{d}$ mode of pollination for outcrossing taxa, e self compatibility, $\mathbf{f}$ seed bank and $\mathbf{g}$ dispersal mode

literature where Competition was found to have more mixed results than supporting (Fig. 5a). Additionally, $28 \%$ of ENA studies and $26 \%$ of EAS studies investigated more than one invasion mechanism. The majority of studies of ENA and EAS species that were investigated for more than one hypothesis found support for multiple invasion hypotheses (13/23 and 
(a) ENA

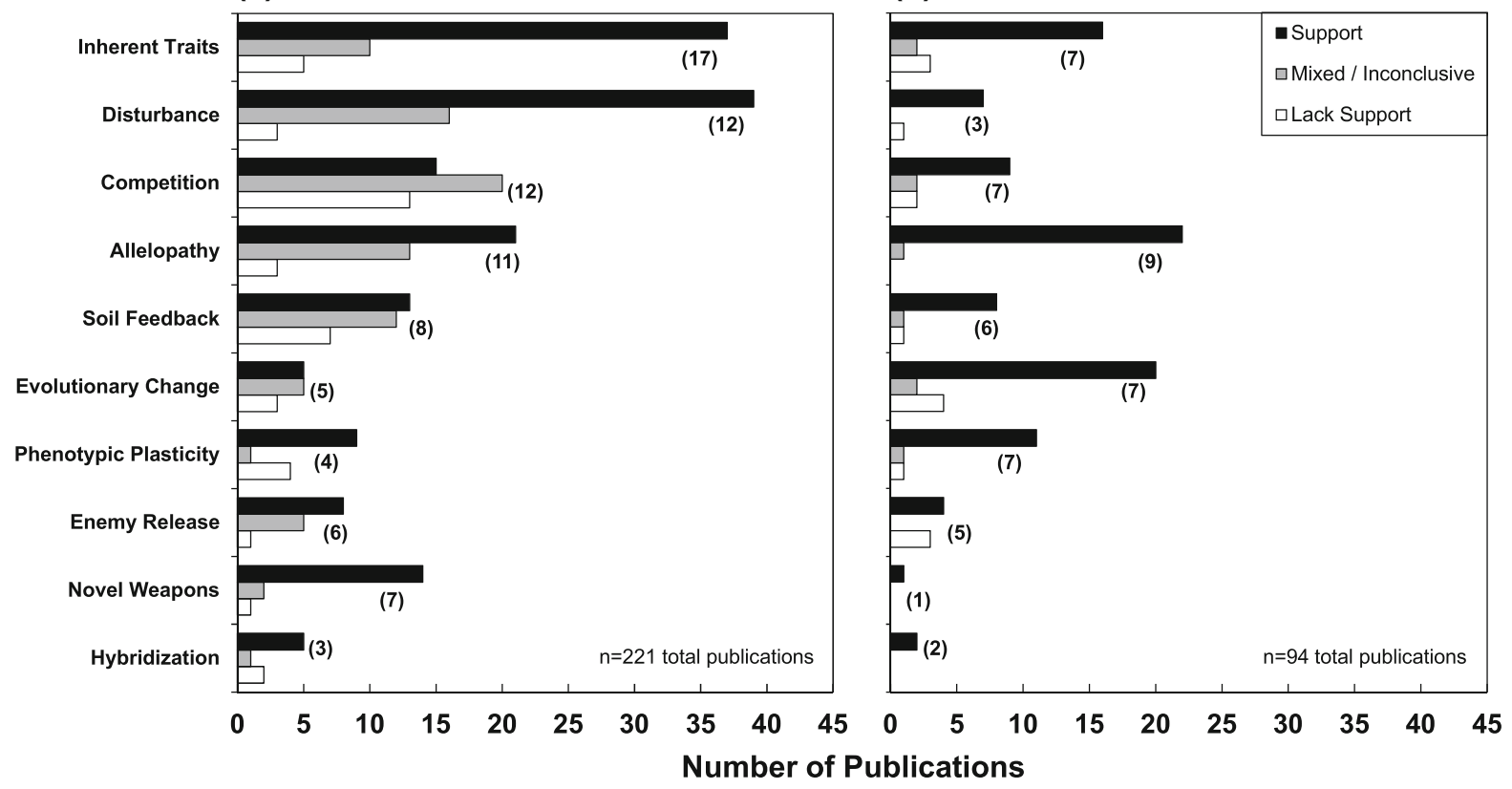

Fig. 5 Results of literature search (315 total publications) on mechanisms of invasion for the compiled list of ENA and EAS forest herbaceous invasive species. For each mechanism, the number of species investigated are given in parentheses

13/17, respectively). Lastly, 8 of the 23 ENA species and 3 of the 17 EAS species found contradicting results for the same mechanism.

It is important to note that a handful of the most 'impactful' invasive species dominated both the EAS and ENA literature searches. For EAS, 64 of the 95 (67\%) studies investigated consisted of literature on just 3 species (species with $>5$ studies). First, Argeratina artemisiifolia contributed 22 studies, 15 of which investigated Evolutionary Change and 12 of those found support, potentially biasing the EAS results for the Evolutionary Change mechanism. Second, Impatiens parviflora contributed 16 studies, with Inherent Traits and Plasticity mechanisms investigated more than the others, but showing more mixed results as opposed to overwhelming support. Lastly, Mikania micrantha contributed 26 studies, 11 of which investigated and found support for Allelopathy (100\% support), and its traits also had $100 \%$ support (though only 4 studies). Second to A. artemisiifolia, it contributed most studies (4) to Evolutionary Change, 3 finding support.

For ENA, 73\% of studies investigated (171/234) were driven by literature on five species (species with $\geq 10$ studies), most of which were just three species (144/234). Of the five species, Alliaria petiolata contributed 40 studies, covering nearly all mechanisms investigated, most of which found majority support. Second, Centaurea solstitialis had 35 studies, potentially biasing the literature against Competition as a mechanism (13 studies, 3 with support), but lending support to Soil Feedback, Inherent Traits, and Disturbance mechanisms. Third, Fallopia japonica contributed 10 studies, with mostly mixed support for Allelopathy, Soil Feedback, and Hybridization. Fourth, Impatiens cylindrica had 17 studies, most of which were Disturbance or Inherent Traits studies with mixed results. Lastly, Microstegium vimineum was the most studied species with 69 studies contributed, overwhelmingly focused on Disturbance (24/29 with support), Competition (mixed results), and Soil Feedback (mixed results).

The ranking of the investigated invasion mechanisms identified by ACA are in general agreement with the manual systematic review with some inconsistencies (Figs. 5, 6a). In ACA results, Disturbance and Soil Feedback were the top two most frequently studied mechanism, followed by Competition, Allelopathy, and Evolutionary Change (Fig. 6a). The most frequent concepts associated with the Disturbance mechanism includes competition, light, seed and seedling, which indicates that past studies on this 
(a)

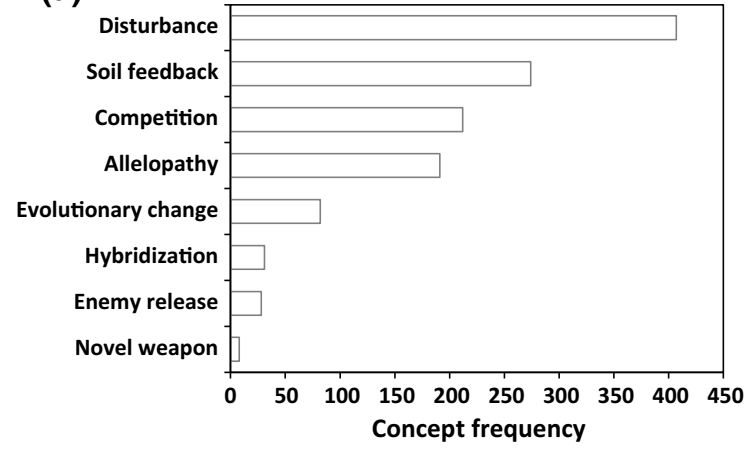

Fig. 6 a Frequency of the nine studied plant invasion mechanisms in the reviewed abstracts. Note, Inherent traits and Plasticity mechanisms were not included in automated

mechanism have focused primarily on the changes biotic and abotic conditions due to disturbance and biotic responses to disturbance in seed and seedling performances. While the top concepts associated with the Soil Feedback mechanism includes litter and microbial, suggesting that past studies have focused on the impacts of invasion on the composition and dynamics of litter and microbial community. Few articles focused on Hybridization, Enemy Release, and Novel Weapon invasion mechanisms.

Interestingly, ACA identified five invasive plants that were extensively tested for these invasion mechanisms (Fig. 6b). M. vimineum, A. petiolata, and $C$. solstitialis were used heavily to test the Disturbance and Competition hypotheses; while $M$. vimineum, $A$. petiolata, and $M$. micrantha were primarily used to test the Soil Feedback hypothesis, which includes alterations of soil microbial communities and nutrient cycling (e.g. Reinhart and Callaway 2006; Coats and Rumpho 2014). A. petiolata, and M. micrantha were the main candidates to test the Allelopathy hypothesis (e.g. Cantor et al. 2011; Brouwer et al. 2015a). All other hypotheses were tested across these top five species but with limited cases.

Temporal dynamics of the key plant invasion mechanisms investigated indicated that most of these invasion hypotheses were only studied in the last 10 years (Fig. S5). For example, for the top two studied mechanisms, Disturbance and Soil Feedback, about $60 \%$ of these concept were accumulated since 2010 and nearly all concepts were accumulated since 2000 in the studied literature. Nearly all key invasion

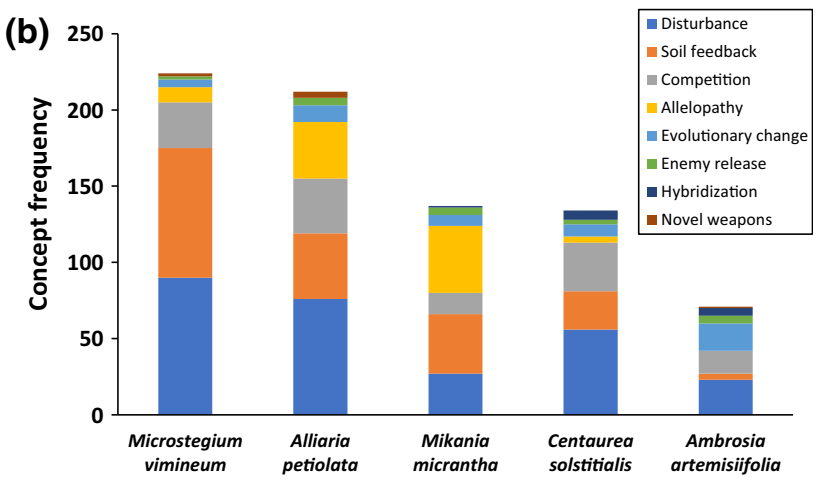

content analysis. b Frequency of invasion mechanisms studied in top five most studied invasive plants

mechanisms had a dramatic increase in the reviewed literature since 2009.

\section{Discussion}

Forest understories are generally considered to be stable and less invaded (Martin et al. 2009). However, this assumption is rarely tested (Taverna et al. 2005) and key mechanisms associated with this assumption such as competition/biotic resistance are still inconclusive (Nunez-Mir et al. 2017). Our systematic literature review found 315 published papers documenting invasion of East Asia (EAS) and Eastern North America (ENA) forest by herbaceous species. We found regional differences in biogeographic donor regions of invaders, differences in both plant families represented and species traits between regions, and that within a single species, multiple invasion mechanism were tested and supported. Many of these studies focus on one or few invaders, which serve as excellent case studies, but broader generalizations are lacking for this important suite of forest invaders.

Biogeographic patterns in understory herbaceous invasions

The contrasting patterns in herbaceous species between EAS and ENA forests are striking- both in terms of taxonomic identity and biogeographic origin, and in the broader context of other habitat invasions within each region. Compared to ENA, the forests of 
EAS are far less invaded in terms of species number; however, proportionally, EAS forest invasions are more likely to be herbaceous than ENA. Surprisingly, no herbaceous species in our analysis are invasive in both regions. This dissimilarity differs from invasions in other habitat types, such as those in high light or agricultural contexts, which are commonly invaded by a similar set of Eurasian herbaceous invaders (Heberling et al. 2017b).

Forest invaders are typified as light-demanding species adapted to forest edge or gaps, which raises the question why they are successful in closed canopy forests? In other words, are these invaders best described as disturbance-adapted, ruderal species of open or anthropogenic habitats that sometimes invade intact closed canopy forests? Forest herb invaders in the present review are common to other habitats types as well, and few (if any) are true forest understory obligates. In terms of number of species, forest invasions are proportionally low relative to those into open habitats in ENA (29\% of all invasions are into forests vs. 74\% into open habitats, Fridley 2008) and even lower in EAS (9\% in forests vs. $75 \%$ in open habitats; Heberling et al. 2017b). Considering only those species of interest in the present review (herbaceous taxa), forest invaders are even rarer (15 and 8\% of invasions for ENA and EAS, respectively). This invasion bias towards high light environments is perhaps not surprising (Martin et al. 2009). It is important to acknowledge that forest understories are increasingly disturbed and invaded, and despite relatively fewer species invading this habitat, their impacts can be dramatic and generate great conservation concern. Most forest invasions are facilitated by human-mediated disturbances, which virturally all forests increasingly experience.

Why does a strong asymmetry in the contributions of forest herb invaders of ENA and EAS exist? This result may be explained in part by varying definitions of "invasive" among regions and the histories of introduction effort, since the origins of the forest herb invaders strongly contrast between regions. This asymmetry for forest herbs is similar to the overall pattern when considering all invasive species across all habitats (Heberling et al. 2017b). Fridley (2013) hypothesized that regional differences in invasion patterns may be a biogeographic signature of past selection pressures in each source region that has led to present day biases for herbaceous invader dominance in EAS and shade tolerant woody species invading ENA. It is interesting that EAS has fewer forest invasions overall, but of these forest invasions, proportionally more are herbaceous than in ENA. It is unclear if this comparative dearth of forest herb invasions in ENA is due to deep historical reasons (Fridley 2013), differences in modern day environments (e.g., disturbances, fragmentation), or simply differences in introduction effort between regions.

Patterns of invader traits and major mechanisms for forest herb invasions

Herbaceous invaders of both EAS and ENA forests tend to exhibit the forb growth form, sexual reproduction but often with self-compatibility, and the formation of long-lived seed banks. The latter two traits combined with perennial life history (Baker 1955, 1965) can contribute to successful population establishment after long distance dispersal where mates or pollinators are scarce (reviewed in Pannell et al. 2015). Thus, the herbaceous understory layer of forests in both of these regions, which are dominated by sexually reproducing perennial forb species that typically form only short-lived seed banks (e.g. Hawkins et al. 2007), are being replaced with the same growth form but not the same life history type or seed bank capacity. Further, considering all herbaceous invasions, most invasive herbs in ENA and EAS are neither shade-tolerant species that originated from forested habitats nor intentional introductions of shade tolerant, late successional species for silviculture or horticulture (Martin et al. 2009). Instead, the majority of EAS and ENA herbaceous invaders are adapted to high light, high resource habitats.

Many native herbaceous species are long-lived perennials with slow growth strategies adapted to low light (Neufeld and Young 2014). Why then are so many ruderal herbaceous species successful as forest invaders? We suggest that one reason may be that although the overstory of a closed canopy forest may appear seemingly intact, the understory may often be disturbed and open by human-mediated direct disturbances (e.g. understory clearing, development of trails, logging, etc.). Temperate forests are increasingly subject to other disturbances globally, including introduced pests and disease outbreaks (Liebhold et al. 2013), N deposition (Gilliam et al. 2016), historically unprecedented increases in ungulate abundance (Côté 
et al. 2004), exotic earthworms (Craven et al. 2017), introduction of multiple nonnative plants ('invasional meltdown'; Simberloff and von Holle 1999), and the interactions of these factors. These disturbances can influence plant invasion success in forests (e.g., Vavra et al. 2007; Nuzzo et al. 2009; Liu et al. 2016). For example, Heberling et al. (2017a), found that both light levels and photosynthetic rates of the ENA herbaceous forest invader, A. petiolata (garlic mustard), are significantly higher for plants growing in areas where deer have free access relative to fenced areas where deer are excluded. Through their effects on leaf litter and belowground dynamics, Nuzzo et al. (2009) found invasive earthworms facilitate the ENA forest herb invaders, A. petiolata and the grass $M$. vimineum, as well as native species composition. Given many forest invasions are at least partly mediated by disturbance, our review findings suggest two management issues. First, managers may want to focus on the combination of ruderal perennial forbs that are self-compatible and form seed banks as key functional traits (sensu Drenovsky et al. 2012) to identify and predict future successful invaders of temperate deciduous forest regions. Further, attention to the agents and level of understory disturbance and action to diminish their effects may be useful for management for a biodiverse forest understory with high regeneration capacity for the overstory.

We acknowledge that our systematic review and automated analyses are based on published studies, which can introduce several sources of bias. First, although most hypotheses tested were supported, this result may reflect true support, or there may be publication bias if studies that find weak or no support are submitted less often or are published less. Further, our syntheses are dominated by a large number of publications on a small number of "important" invaders that are already well established in their invaded range. We lack comparable critical data on "emerging" invaders that could change the weighting of hypotheses. Traits and mechanisms that confer an invader's success likely shift over the time span from its introduction to it becoming "important." The temporal dynamics of invader traits, ecosystem and community responses are also typically lacking and baseline data prior to invasion are rarely in hand, making it difficult to ascribe invader effects conclusively. Moreover, our ACA results could be influenced by the settings and parameters (e.g., size of text segments, list of stopwords, thesaurus settings, etc.) we chose in our analysis. Given these caveats, we explore the implications of our findings.

All leading mechanistic hypotheses (Table 1) have been investigated in herbaceous forest invaders, although to varying degrees and often to specific species. In our systematic review, the most common mechanisms investigated were Inherent Traits of invaders, Disturbance, Competition, and Allelopathy, which are generally consistant with the ACA review but with some inconsistency in terms of rank. This is reasonable given the highly correlative and mutually inexclusive nature among these mechanisms. For example, disturbance co-occurs with competition reduction and allelopathy co-occurs with plant soil feedback. The low numbers of publications testing the other invasion hypotheses may reflect the relatively young age of those hypotheses. The dominance of Inherent Traits stems from many functional trait comparisons of native and non-native plants (van Kleunen et al. 2010, 2014). Studies of allelopathy were especially common for particular invasive forest herb species (e.g., A. petiolata, M. micrantha). Since the majority of native understory herbs rely on mutualisms with mycorrhizae, the potential impact of allelopathic chemicals that disrupt these mutualisms are significant. For example, the allelochemicals of $A$. petiolata (Cantor et al. 2011; Hale and Kalisz 2012) have been found to affect carbon storage and photosynthesis (Hale et al. 2016), demographic performance (Brouwer et al. 2015b) of native understory perennial herbs, and have long-term legacy affects (Lankau et al. 2014). Further, the impacts of these allelopathic or other invader effects on the soil ecosystem, microbial community structure, nutrient cycling and the native community can be long-term and also show legacy effects (Elgersma et al. 2011). Along with the fact that most forest species are long-lived perennials (including many invaders), long-term studies are critically needed to understand the mechanisms behind, and impacts of, most forest herb invasions (Flory and D'Antonio 2015).

Together, our findings suggest that a handful of dominant mechanisms explain most forest herbaceous invasions, but no mechanism was overwhelmingly general. Only a fraction of studies (28\% ENA studies; $26 \%$ EAS) examined more than one mechanism at a time. Of these, $57 \%$ of ENA and $76 \%$ of EAS invaders have published support for more than one invasion 
mechanism. Interestingly, $35 \%$ of ENA invaders and $18 \%$ of EAS invaders have contradicting results for the same mechanism. The diversity of mechanistic hypotheses supported and the contradictory evidence across studies of the same species suggest that mechanistic conclusions can be highly context dependent and idiosyncratic. Likewise, in a global review of tree invasions, Lamarque et al. (2011) also find more than one mechanistic hypothesis for invasion is often supported for a given invasive tree species. Similarly, in a comprehensive systematic review of all biological invasions, Lowry et al. (2013) found that studies tend to only examine one or few hypotheses. There remains a clear need for studies that integrate multiple mechanisms of invaders.

Finally, our review suggests that when herbaceous invaders occupy the forest understory in ENA and EAS, native biodiversity can be lost (e.g. Wiegmann and Waller 2006; Rogers et al. 2008; Winter et al. 2009; Baeten et al. 2010). However, given that these invasions are ongoing, many native forest herbs are long-lived perennials with complex life histories, and forest successional processes are often slower than other habitats, it is unknown whether an extinction debt (sensu Vellend et al. 2006) is accumulating and which species will occupy temperate forest understories in the future.

Heterogeneity of mechanisms underlie invader success: future directions

Our systematic review underscores the idea that individual invader's success does not have a simple, unified explanation across all studies. Rather, herbaceous invader success appears to be driven by multiple factors, combining the species' traits and the ecological and abiotic context of its invasion. We suggest that two factors likely interact to produce the heterogeneity in invaders responses: human influences and the temporal and spatial extent of individual invader studies.

First, it is becoming increasingly clear that anthropogenic changes within ecosystems, rather than the atomized intrinsic traits of individual invaders alone, facilitate or drive most invasions. In plants, invasion typically is initiated when humans purposefully or accidentally transport species far beyond the regions where they originated and evolved. Further, humans are the ultimate ecosystem engineers (Jones et al.
1994), combining climate change and habitat alterations into a "deadly anthropogenic cocktail" (Travis 2003) that alters the abiotic conditions and biotic interactions that can open the environmental door for invaders (Dukes and Mooney 1999), and perhaps more so than for native species (Liu et al. 2016).

Second, extrinsic anthropogenic factors exist and interact on different spatial scales. On a continental to regional scale, humans modify species dispersal patterns beyond their historical geographic ranges and place species into novel abiotic environments and ecological contexts. On a more local scale, humans alter environmental suitability for native species through changes in land use patterns, habitat disturbance, fragmentation, and logging, while on a global scale, climate change including altered temperature or rainfall patterns, eutrophication and $\mathrm{N}$ deposition change conditions that can favor invasive species over natives (Gilliam 2006). These unintended alterations of the habitat in combination with purposeful (mis)management of native species can profoundly change local biotic interactions (e.g., predator loss and enemy release, trophic downgrading, trophic cascades, plant-soil feedbacks, changes in competitive hierarchies) that can favor invasive plant species.

As considerable heterogeneities exist both within and across different regions (e.g., population density, propagule pressure), the effect size of the aforementioned mechanisms on invasion processes will likely vary across scale and across different taxonomic groups. Unfortunately, most of our invasion knowledge derives primarily from small spatial scale studies. Depending on the study locations and species involved, inconsistent results across studies are to be expected. As noted by Jeschke et al. (2012), the support for all major invasion hypotheses has declined over time. One major reason for the decline is the lack of the consideration of heterogeneity in these small scale studies and the lack of mechanistic understanding of the factors contributing to the emergence of large scale invasion patterns. Another is that invaders can evolve in situ. To attain greater mechanistic understanding and more robust predictions of invasion processes, we urgently need a holistic, time scaledependent framework across taxonomic groups that considers spatial heterogeneity and the interactions among natural and anthropogenic factors to study exotic invasions. 
Acknowledgements SF was partially supported by National Science Foundation Macrosystems Biology (Grant Numbers 1241932 and 1638702). MW gives special thanks to K. Patel, D. Malagon, and C. Sheppard for help with data collection. SK was partially support by NSF DEB 1457531 and the University of Tennessee, Knoxville. JMH was partially supported by NSF DEB 1457531 award to SK and by a NSF Postdoctoral Fellowship in Biology (NSF 1612079). The authors are grateful to the Kalisz lab for helpful comments on this manuscript and appreciate the insightful comments by the three reviewers, which greatly improved the manuscript.

Open Access This article is distributed under the terms of the Creative Commons Attribution 4.0 International License (http:// creativecommons.org/licenses/by/4.0/), which permits unrestricted use, distribution, and reproduction in any medium, provided you give appropriate credit to the original author(s) and the source, provide a link to the Creative Commons license, and indicate if changes were made.

\section{References}

Abbott RJ (1992) Plant invasions, interspecific hybridization and the evolution of new plant taxa. Trends Ecol Evol 7:401-405

Alpert P, Bone E, Holzapfel C (2000) Invasiveness, invasibility and the role of environmental stress in the spread of nonnative plants. Perspect Plant Ecol Evol Syst 3:52-66

Baeten L, Hermy M, Van Daele S, Verheyen K (2010) Unexpected understorey community development after 30 years in ancient and post-agricultural forests. J Ecol 98:1447-1453

Baker HG (1955) Self-compatibility and establishment after 'long-distance' dispersal. Evolution 9:347-349

Baker HG (1965) Characteristics and modes of origins of weeds. In: Baker HG, Stebbins GL (eds) The genetics of colonizing species. Academic Press, New York, pp 147-172

Baker TT, Van Lear DH (1998) Relations between density of rhododendron thickets and diversity of riparian forests. For Ecol Manag 109:21-32

Blossey B, Notzold R (1995) Evolution of increased competitive ability in invasive nonindigenous plants: a hypothesis. J Ecol 83:887-889

Boufford DE, Spongberg SA (1983) Eastern Asian-eastern North American phytogeographical relationships-a history from the time of linnaeus to the twentieth century. Ann Mo Bot Gard 70:423-439

Brouwer NL, Hale AN, Kalisz S (2015a) Mutualism-disrupting allelopathic invader drives carbon stress and vital rate decline in a forest perennial herb. AoB Plants 7:plv014

Brouwer NL, Hale AN, Kalisz S (2015b) Invader disruption of a belowground mutualism drives carbon starvation and vital rate declines in a native forest perennial herb. AoB Plants. doi:10.1093/aobpla/plv014

Bryant D, Nielsen D, Tangley L, Sizer N, Miranda M, Brown P, Johnson N, Malk A, Miller K (1997) The last frontier forests: ecosystems and economies on the edge. What is the status of the worlds remaining large natural forest ecosystems? World Resources Institute, Forest Frontiers Initiative, Washington, D.C

Callaway RM, Ridenour WM (2004) Novel weapons: invasive success and the evolution of increased competitive ability. Front Ecol Environ 2:436-443

Cantor A, Hale A, Aaron J, Traw MB, Kalisz S (2011) Low allelochemical concentrations detected in garlic mustardinvaded forest soils inhibit fungal growth and AMF spore germination. Biol Invasions 13:3015-3025

Clavel J, Julliard R, Devictor V (2011) Worldwide decline of specialist species: toward a global functional homogenization? Front Ecol Environ 9:222-228

Coats VC, Rumpho ME (2014) The rhizosphere microbiota of plant invaders: an overview of recent advances in the microbiomics of invasive plants. Front Microbiol 5:368

Côté SD, Rooney TP, Tremblay J-P, Dussault C, Waller DM (2004) Ecological impacts of deer overabundance. Annu Rev Ecol Evol Syst 35:113-147

Craven D, Thakur MP, Cameron EK, Frelich LE, Beauséjour R, Blair RB, Blossey B, Burtis J, Choi A, Dávalos A, Fahey TJ, Fisichelli NA, Gibson K, Handa IT, Hopfensperger K, Loss SR, Nuzzo V, Maerz JC, Sackett T, Scharenbroch BC, Smith SM, Vellend M, Umek LG, Eisenhauer N (2017) The unseen invaders: introduced earthworms as drivers of change in plant communities in North American forests (a meta-analysis). Glob Change Biol 23:1065-1074

Daehler CC (2003) Performance comparisons of co-occurring native and alien invasive plants: implications for conservation and restoration. Annu Rev Ecol Evol Syst 34:183-211

Davidson AM, Jennions M, Nicotra AB (2011) Do invasive species show higher phenotypic plasticity than native species and if so, is it adaptive? A meta-analysis. Ecol Lett 14:419-431

Debinski DM, Holt RD (2000) Review: a survey and overview of habitat fragmentation experiments. Conserv Biol 14: 342-355

Devine K, Fei S (2011) A review of impacts by invasive exotic plants on forest ecosystem services. In: Fei S (ed) Proceedings of the 17th Central Hardwood Forest Conference, Newtown Square, Pennsylvania, USDA Forest Service, Northern Research Station, pp 425-435

Donoghue MJ, Smith SA (2004) Patterns in the assembly of temperate forests around the northern hemisphere. Philos Trans Biol Sci 359:1633-1644

Drenovsky RE, Grewell BJ, D’Antonio CM, Funk JL, James JJ, Molinari N, Parker IM, Richards CL (2012) A functional trait perspective on plant invasion. Ann Bot 110:141-153

Dukes JS, Mooney HA (1999) Does global change increase the success of biological invaders? Trends Ecol Evol 14:135139

Ehrenfeld JG (2003) Effects of exotic plant invasions on soil nutrient cycling processes. Ecosystems 6:503-523

Ehrenfeld JG (2010) Ecosystem consequences of biological invasions. Annu Rev Ecol Evol Syst 41:59-80

Elgersma KJ, Ehrenfeld JG, Yu S, Vor T (2011) Legacy effects overwhelm the short-term effects of exotic plant invasion and restoration on soil microbial community structure, enzyme activities, and nitrogen cycling. Oecologia 167:733745 
Ellstrand NC, Schierenbeck KA (2000) Hybridization as a stimulus for the evolution of invasiveness in plants? Proc Natl Acad Sci USA 97:7043-7050

Elser JJ, Bracken ME, Cleland EE, Gruner DS, Harpole WS, Hillebrand H, Ngai JT, Seabloom EW, Shurin JB, Smith JE (2007) Global analysis of nitrogen and phosphorus limitation of primary producers in freshwater, marine and terrestrial ecosystems. Ecol Lett 10:1135-1142

Fei S, Phillips J, Shouse M (2014) Biogeomorphic impacts of invasive species. Annu Rev Ecol Evol Syst 45:69-87

Flory SL, D'Antonio CM (2015) Taking the long view on the ecological effects of plant invasions. Am J Bot 102:817818

Fridley JD (2008) Of Asian forests and European fields: eastern US plant invasions in a global floristic context. PLoS ONE 3:e3630

Fridley JD (2013) Plant invasions across the Northern Hemisphere: a deep-time perspective. Ann N Y Acad Sci 1293: $8-17$

Friedland AJ, Jones RT, Gross TF, Blackmer SD (2004) Towards a sustainable northern forest: forest health and potential threats. J Sustain For 18:1-22

Gilliam FS (2006) Response of the herbaceous layer of forest ecosystems to excess nitrogen deposition. J Ecol 94:11761191

Gilliam FS (2007) The ecological significance of the herbaceous layer in temperate forest ecosystems. Bioscience $57: 845-858$

Gilliam FS (2014) The herbaceous layer in forests of eastern North America. Oxford University Press, Oxford

Gilliam FS, Welch NT, Phillips AH, Billmyer JH, Peterjohn WT, Fowler ZK, Walter CA, Burnham MB, May JD, Adams MB (2016) Twenty-five-year response of the herbaceous layer of a temperate hardwood forest to elevated nitrogen deposition. Ecosphere 7:1-16

Guo Q (1999) Ecological comparisons between Eastern Asia and North America: historical and geographical perspectives. J Biogeogr 26:199-206

Hale AN, Kalisz S (2012) Perspectives on allelopathic disruption of plant mutualisms: a framework for individual-and population-level fitness consequences. Plant Ecol 213:1991-2006

Hale AN, Lapointe L, Kalisz S (2016) Invader disruption of belowground plant mutualisms reduces carbon acquisition and alters allocation patterns in a native forest herb. New Phytol 209:542-549

Hawkins TS, Baskin JM, Baskin CC (2007) Seed morphology, germination phenology, and capacity to form a seed bank in six herbaceous layer Apiaceae species of the Eastern Deciduous Forest. Castanea 72:8-14

Heberling JM, Brouwer NL, Kalisz S (2017a) Effects of deer on the photosynthetic performance of invasive and native forest herbs. AoB Plants 9:plx011

Heberling JM, Jo I, Kozhevnikov A, Lee H, Fridley JD (2017b) Biotic interchange in the Anthropocene: strong asymmetry in East Asian and Eastern North American plant invasions. Glob Ecol Biogeogr 26:447-458.

Hierro JL, Callaway RM (2003) Allelopathy and exotic plant invasion. Plant Soil 256:29-39

Hierro JL, Villarreal D, Eren Ö, Graham JM, Callaway RM (2006) Disturbance facilitates invasion: the effects are stronger abroad than at home. Am Nat 168:144-156
Hooper DU, Chapin F, Ewel J, Hector A, Inchausti P, Lavorel S, Lawton J, Lodge D, Loreau M, Naeem S (2005) Effects of biodiversity on ecosystem functioning: a consensus of current knowledge. Ecol Monogr 75:3-35

Iannone BV, Oswalt CM, Liebhold AM, Guo Q, Potter KM, Nunez-Mir GC, Oswalt SN, Pijanowski BC, Fei S (2015) Region-specific patterns and drivers of macroscale forest plant invasions. Divers Distrib 21:1181-1192

Jeschke J, Aparicio LG, Haider S, Heger T, Lortie C, Pyšek P, Strayer D (2012) Support for major hypotheses in invasion biology is uneven and declining. NeoBiota 14:1

Jolls C (2003) Populations of and threats to rare plants of the herb layer: more challenges and opportunities for conservation biologists. In: Gilliam FS, Roberts MR (eds) The herbaceous layer in forests of Eastern North America. Oxford University Press, New York, pp 105-162

Jones CG, Lawton JH, Shachak M (1994) Organisms as ecosystem engineers. Ecosystem management. Springer, Berlin, pp 130-147

Kalisz S, Spigler R, Horvitz C (2014) In a long-term experimental demography study, excluding ungulates reversed invader's explosive population growth rate and restored natives. Proc Natl Acad Sci 111:4501-4506

Keane RM, Crawley MJ (2002) Exotic plant invasions and the enemy release hypothesis. Trends Ecol Evol 17:164-170

Keith SA, Newton AC, Morecroft MD, Bealey CE, Bullock JM (2009) Taxonomic homogenization of woodland plant communities over 70 years. Proc R Soc Lond B Biol Sci 276:3539-3544

Lamarque LJ, Delzon S, Lortie CJ (2011) Tree invasions: a comparative test of the dominant hypotheses and functional traits. Biol Invasions 13:1969-1989

Lankau RA, Bauer JT, Anderson MR, Anderson RC (2014) Long-term legacies and partial recovery of mycorrhizal communities after invasive plant removal. Biol Invasions 16:1979-1990

LeBauer DS, Treseder KK (2008) Nitrogen limitation of net primary productivity in terrestrial ecosystems is globally distributed. Ecology 89:371-379

Levine JM, Adler PB, Yelenik SG (2004) A meta-analysis of biotic resistance to exotic plant invasions. Ecol Lett 7:975-989

Liebhold AM, McCullough DG, Blackburn LM, Frankel SJ, Von Holle B, Aukema JE (2013) A highly aggregated geographical distribution of forest pest invasions in the USA. Divers Distrib 19:1208-1216

Liu Y, Oduor AMO, Zhang Z, Manea A, Tooth IM, Leishman MR, Xu X, van Kleunen M (2016) Do invasive alien plants benefit more from global environmental change than native plants? Glob Change Biol. doi:10.1111/gcb.13579

Lowry E, Rollinson EJ, Laybourn AJ, Scott TE, Aiello-Lammens ME, Gray SM, Mickley J, Gurevitch J (2013) Biological invasions: a field synopsis, systematic review, and database of the literature. Ecol Evol 3:182-196

Luken JO (2014) Forest invasions: perceptions, impacts, and management questions. In: Gilliam FS (ed) The herbaceous layer in forests of Eastern North America, pp. 356-368. Oxford University Press, New York

Maron JL, Vila M (2001) When do herbivores affect plant invasion? Evidence for the natural enemies and biotic resistance hypotheses. Oikos 95:361-373 
Martin PH, Canham CD, Marks PL (2009) Why forests appear resistant to exotic plant invasions: intentional introductions, stand dynamics, and the role of shade tolerance. Front Ecol Environ 7:142-149

Martin J-L, Stockton SA, Allombert S, Gaston AJ (2010) Topdown and bottom-up consequences of unchecked ungulate browsing on plant and animal diversity in temperate forests: lessons from a deer introduction. Biol Invasions 12:353-371

Meisner A, Hol WG, de Boer W, Krumins JA, Wardle DA, van der Putten WH (2014) Plant-soil feedbacks of exotic plant species across life forms: a meta-analysis. Biol Invasions 16:2551-2561

Mouillot D, Graham NA, Villéger S, Mason NW, Bellwood DR (2013) A functional approach reveals community responses to disturbances. Trends Ecol Evol 28:167-177

Mueller KE, Eissenstat DM, Hobbie SE, Oleksyn J, Jagodzinski AM, Reich PB, Chadwick OA, Chorover J (2012) Tree species effects on coupled cycles of carbon, nitrogen, and acidity in mineral soils at a common garden experiment. Biogeochemistry 111:601-614

Murphy GE, Romanuk TN (2014) A meta-analysis of declines in local species richness from human disturbances. Ecol Evol 4:91-103

Neufeld HS, Young DR (2014) Ecophysiology of the herbaceous layer in temperate deciduous forests. Oxford University Press, Oxford

Nunez-Mir GC, Iannone BV, Pijanowski BC, Kong N, Fei S (2016) Automated content analysis: addressing the big literature challenge in ecology and evolution. Methods Ecol Evol 7(11):1262-1272

Nunez-Mir GC, Liebhold AM, Guo Q, Brockerhoff EG, Jo I, Ordonez K, Fei S (2017) Biotic resistance to exotic invasions: its role in forest ecosystems, confounding artifacts, and future directions. Biol Invasions. doi:10.1007/s10530017-1413-5

Nuzzo VA, Maerz JC, Blossey B (2009) Earthworm invasion as the driving force behind plant invasion and community change in northeastern North American forests. Conserv Biol 23:966-974

Oswalt CM, Fei S, Iannone B, Oswalt S, Pijanowski B, Potter K (2015) A subcontinental view of forest plant invasions using national inventory data. NeoBiota 24:49-54

Pannell JR, Auld JR, Brandvain Y, Burd M, Busch JW, Cheptou PO, Conner JK, Goldberg EE, Grant AG, Grossenbacher DL (2015) The scope of Baker's law. New Phytol 208:656-667

Prentis PJ, Wilson JR, Dormontt EE, Richardson DM, Lowe AJ (2008) Adaptive evolution in invasive species. Trends Plant Sci 13:288-294

Qian H, Ricklefs RE (1999) A comparison of the taxonomic richness of vascular plants in China and the United States. Am Nat 154:160-181

Qian H, Ricklefs RE (2000) Large-scale processes and the Asian bias in species diversity of temperate plants. Nature 407:180-182

Qian H, Ricklefs RE (2006) The role of exotic species in homogenizing the North American flora. Ecol Lett 9:1293-1298

Reinhart KO, Callaway RM (2006) Soil biota and invasive plants. New Phytol 170:445-457
Richardson DM, Rejmánek M (2011) Trees and shrubs as invasive alien species-a global review. Divers Distrib 17:788-809

Roberts MR (2004) Response of the herbaceous layer to natural disturbance in North American forests. Can $\mathrm{J}$ Bot 82:1273-1283

Roberts MR, Gilliam FS (2003) Response of the herbaceous layer to disturbance in eastern forests. The herbaceous layer in forests of eastern North America. Oxford University Press, Oxford, pp 302-320

Rodgers VL, Wolfe BE, Werden LK, Finzi AC (2008) The invasive species Alliaria petiolata (garlic mustard) increases soil nutrient availability in northern hardwoodconifer forests. Oecologia 157:459-471

Rogers DA, Rooney TP, Olson D, Waller DM (2008) Shifts in southern Wisconsin forest canopy and understory richness, composition, and heterogeneity. Ecology 89:2482-2492

Rooney TP, Wiegmann SM, Rogers DA, Waller DM (2004) Biotic impoverishment and homogenization in unfragmented forest understory communities. Conserv Biol 18:787-798

Rothstein DE (2000) Spring ephemeral herbs and nitrogen cycling in a northern hardwood forest: an experimental test of the vernal dam hypothesis. Oecologia 124:446-453

Royo AA, Carson WP (2006) On the formation of dense understory layers in forests worldwide: consequences and implications for forest dynamics, biodiversity, and succession. Can J For Res 36:1345-1362

Royo AA, Stout SL, Pierson TG (2010) Restoring forest herb communities through landscape-level deer herd reductions: is recovery limited by legacy effects? Biol Conserv 143:2425-2434

Sala OE, Chapin FS, Armesto JJ, Berlow E, Bloomfield J, Dirzo R, Huber-Sanwald E, Huenneke LF, Jackson RB, Kinzig A (2000) Global biodiversity scenarios for the year 2100 . Science 287:1770-1774

Simberloff D, Von Holle B (1999) Positive interactions of nonindigenous species: invasional meltdown? Biol Invasions 1:21-32

Smith AE, Humphreys MS (2006) Evaluation of unsupervised semantic mapping of natural language with Leximancer concept mapping. Behav Res Methods 38:262-279

Spyreas G, Matthews JW (2006) Floristic conservation value, nested understory floras, and the development of secondgrowth forest. Ecol Appl 16:1351-1366

Takhtajan AL, Crovello TJ, Cronquist A (1986) Floristic regions of the world. University of California Press, Berkeley

Taverna K, Peet RK, Phillips LC (2005) Long-term change in ground-layer vegetation of deciduous forests of the North Carolina Piedmont, USA. J Ecol 93:202-213

Tessier JT, Raynal DJ (2003) Vernal nitrogen and phosphorus retention by forest understory vegetation and soil microbes. Plant Soil 256:443-453

Tews J, Brose U, Grimm V, Tielbörger K, Wichmann MC, Schwager M, Jeltsch F (2004) Animal species diversity driven by habitat heterogeneity/diversity: the importance of keystone structures. J Biogeogr 31:79-92

Thompson Reuters (2016) Web of science, n.d. Web. July \& aug. 2016

Travis J (2003) Climate change and habitat destruction: a deadly anthropogenic cocktail. Proc R Soc Lond B Biol Sci 270:467-473 
Van Der Heijden MG, Horton TR (2009) Socialism in soil? The importance of mycorrhizal fungal networks for facilitation in natural ecosystems. J Ecol 97:1139-1150

Van der Heijden MG, Klironomos JN, Ursic M, Moutoglis P (1998) Mycorrhizal fungal diversity determines plant biodiversity, ecosystem variability and productivity. Nature 396:69

Van Kleunen M, Weber E, Fischer M (2010) A meta-analysis of trait differences between invasive and non-invasive plant species. Ecol Lett 13:235-245

Van Kleunen M, Dawson W, Maurel N (2014) Characteristics of successful alien plants. Mol Ecol 24:1954-1968

Vavra M, Parks CG, Wisdom MJ (2007) Biodiversity, exotic plant species, and herbivory: the good, the bad, and the ungulate. For Ecol Manag 246:66-72

Vellend M, Verheyen K, Jacquemyn H, Kolb A, Van Calster H, Peterken G, Hermy M (2006) Extinction debt of forest plants persists for more than a century following habitat fragmentation. Ecology 87:542-548

Verhoeven KJ, Biere A, Harvey JA, Van Der Putten WH (2009) Plant invaders and their novel natural enemies: who is naive? Ecol Lett 12:107-117

Vilà M, Espinar JL, Hejda M, Hulme PE, Jarošík V, Maron JL, Pergl J, Schaffner U, Sun Y, Pyšek P (2011) Ecological impacts of invasive alien plants: a meta-analysis of their effects on species, communities and ecosystems. Ecol Lett 14:702-708

Walsh JR, Carpenter SR, Vander Zanden MJ (2016) Invasive species triggers a massive loss of ecosystem services through a trophic cascade. Proc Natl Acad Sci 113:4081-4085
Warren RJ, Wright JP, Bradford MA (2011) The putative niche requirements and landscape dynamics of Microstegium vimineum: an invasive Asian grass. Biol Invasions 13:471-483

Welch NT, Belmont JM, Randolph J (2007) Summer ground layer biomass and nutrient contribution to above-ground litter in an Indiana temperate deciduous forest. Am Midl Nat 157:11-26

Wen J (1999) Evolution of eastern Asian and eastern North American disjunct distributions in flowering plants. Annu Rev Ecol Syst 30:421-455

Whitney KD, Gabler CA (2008) Rapid evolution in introduced species, 'invasive traits' and recipient communities: challenges for predicting invasive potential. Divers Distrib 14:569-580

Wiegmann SM, Waller DM (2006) Fifty years of change in northern upland forest understories: identity and traits of "winner" and "loser" plant species. Biol Conserv 129:109-123

Winter M, Schweiger O, Klotz S, Nentwig W, Andriopoulos P, Arianoutsou M, Basnou C, Delipetrou P, Didžiulis V, Hejda M (2009) Plant extinctions and introductions lead to phylogenetic and taxonomic homogenization of the European flora. Proc Natl Acad Sci 106:21721-21725

Wolfe BE, Klironomos JN (2005) Breaking new ground: soil communities and exotic plant invasion. Bioscience 55:477-487

Zak DR, Grigal DF, Gleeson S, Tilman D (1990) Carbon and nitrogen cycling during old-field succession: constraints on plant and microbial biomass. Biogeochemistry 11:111-129 